\title{
Physical activity and persons with intellectual disability: some considerations for Latin America
}

\author{
Viviene A Temple, PhD, (') Heidi I Stanish, PhD.(2)
}

\begin{abstract}
Temple VA, Stanish HI.
Physical activity and persons with intellectual disability: some considerations for Latin America. Salud Publica Mex 2008;50 suppl 2:S I85-SI 93.
\end{abstract}

\begin{abstract}
Physical activity is a personal and societal investment in health. In Latin America, rates of non-communicable diseases are growing and there is burgeoning interest in physical activity as a preventative health measure.This paper describes physical activity among adults with intellectual disability from a public health perspective; and provides recommendations related to the need for, and measurement of, physical activity among persons with intellectual disability in Latin America.
\end{abstract}

Key words: intellectual disability; physical activity; health benefits; non-communicable diseases; Latin America
Temple VA, Stanish HI.

Actividad física en personas con discapacidad intelectual: algunas consideraciones para América Latina.

Salud Publica Mex 2008;50 supl 2:SI85-SI93.

\section{Resumen}

La actividad física es una inversión en salud, tanto personal como social. En América Latina las tasas de enfermedades no transmisibles van en aumento y existe un creciente interés en la actividad física como medida de salud preventiva. Este artículo describe la actividad física entre adultos con discapacidad intelectual desde la perspectiva de la salud pública y proporciona recomendaciones pertinentes a la necesidad y medición de la actividad física entre personas con discapacidad intelectual en América Latina.

Palabras clave: discapacidad intelectual; actividad física; beneficios a la salud; enfermedades no transmisibles; América Latina
$\mathrm{O}$ ne of three objectives of the Pan American Regional Strategy on Nutrition in Health and Development 2006-2015 is "To promote the adoption of healthy dietary habits, active lifestyles, the control of obesity- and nutrition-related chronic diseases". ${ }^{1}$ The aim of this paper is to describe what is known about participation by adults with intellectual disability in physical activity consistent with public health recommendations and discuss the need to, and process of, measuring physi- cal activity among persons with intellectual disability in Latin America.

\section{Benefits of physical activity}

"Over the last decade there has been an increasing body of evidence supporting active lifestyles as one of the best investments for individual and community health". ${ }^{2}$ National and international organizations such as the

(I) School of Physical Education, University of Victoria, BC, Canada.

(2) Department of Exercise Science and Physical Education, University of Massachusetts Boston, USA. 
World Health Organization (WHO) have identified that accruing 30 minutes of moderate intensity physical activity (3.5-7 kilocalories per minute or 3.0-6.0 metabolic equivalents) on most, preferably all, days of the week serves as a preventative health measure., Engaging in regular moderate intensity physical activity, such as brisk walking, has protective effects for several chronic diseases, including coronary heart disease, hypertension, type 2 diabetes, osteoporosis, and colon cancer. ${ }^{5}$ In addition, strength and balance training can reduce the risk of falls and increase functional status among older people. ${ }^{4}$

In a discussion on physical activity and sedentary behavior, Vuori' ${ }^{6}$ notes that the health benefits associated with physical activity are more wide-ranging than the mere absence of disease. Physical activity is a vital biological stimulus needed to maintain the structure and function of the body's organs and organ systems. ${ }^{6}$ In addition, regular physical activity is associated with reduced anxiety and depression, ${ }^{5}$ enhanced social inclusion, ${ }^{7}$ and a sense of belonging. ${ }^{7}$ Physical activity reduces overall adiposity in a dose-response relationship, ${ }^{8}$ helps maintain muscle mass when dieting, ${ }^{8}$ and has positive effects on fat metabolism. ${ }^{9}$ It has been demonstrated that individuals considered to have metabolic syndrome [three or more of: high blood pressure, high blood glucose, high plasma triglycerides, low HDL cholesterol, abdominal obesity ${ }^{10}$ respond positively to aerobic physical activity]. ${ }^{11}$ In addition, when fat oxidation has been effected by chronic undernutrion during growth and development, increasing physical activity to levels over 1.8 times resting metabolic rate (that is, being physically active) accelerates fat oxidation whereas sedentary behavior (1.4 times resting metabolic rate) does not. ${ }^{9}$

Physical activity, and strength training in particular, can help improve bone health ${ }^{12}$ and physical functioning ${ }^{13}$ as people age. The risk of osteoporotic fractures is lower among active individuals because of higher bone density and decreased risk of falling associated with better balance, strength, range of motion, and more stable gait. ${ }^{14}$

The health benefits of physical activity have been recognized for more than 30 years. In addition to preventing many non-communicable diseases, physical activity can enhance physical, mental, and social wellbeing, as well as quality of life.

\section{Health risks associated with inactivity among adults with intellectual disability}

It is well documented that people with intellectual disability experience high rates of morbidity and mortality associated with non-communicable diseases. ${ }^{15}$ People with intellectual disability have higher rates of diabetes, high blood pressure, cardiovascular disease, and obesity than adults without intellectual disability, ${ }^{16-20}$ and low levels of physical fitness. ${ }^{21,22}$ Draheim ${ }^{16}$ explained that although deaths from cardiovascular disease in the United States have declined over the last 30 years, there has not been a comparable decline in deaths among adults with intellectual disability. Draheim argued that adults with intellectual disability, particularly those who live in the community, were more susceptible to the risk factors for cardiovascular disease, such as obesity, smoking, and sedentary lifestyles.

Findings related to osteoporosis and low bone mass among adults with intellectual disability are ambiguous. Several studies indicate that rates of osteoporosis are higher among adults with intellectual disability than the general population (for example ${ }^{23,24}$ ) whereas other studies reveal no differences between groups after controlling for age and body mass index. ${ }^{25,26}$ Whether the prevalence of osteoporosis differs between adults with intellectual disability and those without intellectual disability is unclear; however, many adults with intellectual disability have low bone density as well as numerous risk factors for osteoporosis. ${ }^{23,26}$ These health profiles are attributed to and suggestive of highly sedentary behavior, but there is a scarcity of data to support this conclusion.

\section{Physical activity behavior of adults with intellectual disability}

In a recent literature review, Temple, et al. ${ }^{27}$ evaluated 801 citations produced from key word searches for the terms mental retardation, intellectual disability, learning disability, or developmental disability combined with physical activity or habitual exercise. Of the abstracts reviewed, 14 articles examined some form of participation in physical activity. All of the studies were conducted in 'developed' countries, specifically Australia, Canada, the United States, and England. The categorization of nations as 'developed' or 'developing' can be contentious. The use of these terms in this article is informed by the work of Fujiura, et al..$^{28}$ On a pragmatic level, developed nations are the United States, Canada, countries of Western Europe, Australia, New Zealand, and established market economies of Asia (Japan, South Korea, and Taiwan). Of the 14 articles reviewed by Temple and coworkers, eight investigated participation in physical activity consistent with a health-related criterion (table I). The following is a brief synopsis of the major findings of these studies.

The three studies that assessed physical activity using accelerometers ${ }^{29-31}$ indicate that approximately one 
Table I

EXTENT TO WHICH ADULTS WITH INTELLECTUAL DISABILITY MEET SPECIFIC HEALTH-RELATED PHYSICAL ACTIVITY CRITERIA

\begin{tabular}{|c|c|c|c|c|}
\hline Authors & Health-related criterion & Country & $N$ & $\%$ meeting guideline \\
\hline \multirow[t]{2}{*}{ Stanish \& Draheim (2005) } & 30-min. moderate to vigorous PA & Canada & 103 & $M V P A=17.5 \%$ \\
\hline & $\geq 5$ days/week*; 10,000 steps/day ${ }^{\ddagger}$ & & & Steps: $21 \%$ \\
\hline Emerson (2005) & Mod. - vig. PA x 20 min. $12 / 4$ weeks $\S$ & England & 1458 & $4 \%$ \\
\hline \multirow[t]{2}{*}{ Stanish (2004) } & 10,000 steps $/$ day $\ddagger$ & Canada & 20 & $45 \%$ on weekdays, \\
\hline & & & & $20 \%$ on weekend \\
\hline Frey (2004) & 30-min. of moderate-hard PA/day* & United States & 22 & $28 \% \#$ \\
\hline Temple \& Walkley (2003) & 30-min. moderate PA/day\& & Australia & 37 & $32 \%$ \\
\hline Temple et al. (2000) & 30-min. moderate $\mathrm{PA} \geq 5$ days/week ${ }^{\&}$ & Australia & 6 & $33 \%$ \\
\hline Robertson et al. (2000) & Mod. - vig. PA x $20 \mathrm{~min} .12 / 4$ weeks $^{\neq}$ & England & 500 & $7-20 \%$ \\
\hline Messent et al. (1998a) & $3 \times 20$ min. moderate PA/week ${ }^{\neq}$ & England & 24 & $8 \%$ \\
\hline \multicolumn{5}{|c|}{ * U.S. Department of Health and Human Services (1996) } \\
\hline \multicolumn{5}{|c|}{ ¥ Tudor-Locke and Bassett (2004) } \\
\hline \multicolumn{5}{|c|}{$\S$ National Centre for Social Research (2002) } \\
\hline \multicolumn{5}{|c|}{ \# These data were extracted through follow up with the author } \\
\hline \multicolumn{5}{|c|}{ \& Commonwealth Department of Health and Aged Care (1999) } \\
\hline \multicolumn{5}{|c|}{ F Department of Health (1995) } \\
\hline \multicolumn{5}{|l|}{$\mathrm{PA}=$ physical activity } \\
\hline MVPA= moderate-vigoro & & & & \\
\hline
\end{tabular}

third of ambulatory adults with mild or moderate intellectual disability are sufficiently active to accrue health benefits. Temple and coworkers ${ }^{30}$ used direct observation and accelerometry to record the physical activity behavior of six (three men and three women) individuals with intellectual disability over seven consecutive days. Direct observation data revealed that two participants achieved 30-minutes of moderate intensity physical activity per day. Moderate intensity physical activity was accrued mainly via walking for transport and gardening as part of supported employment. A follow-up study by Temple and Walkley ${ }^{31}$ examined participation in physical activity via 3-day diary recording $\mathrm{s}^{32}$ completed by proxy respondents and via accelerometry. Participants were 37 adults living in supported group homes with mild to moderate intellectual disability. Data were collected for three days; two weekdays and one weekend day. On average, participants accrued more than 1-hour per day of moderate intensity physical activity. As previously observed by Temple and coworkers, ${ }^{30}$ there was considerable between-subject variability. Only 32\% of participants met the recommended 30-minutes of moderate intensity physical activity per day despite the group average of 68 minutes per day. Frey ${ }^{29}$ reported similar findings based on a comparison of physical activity levels between adults with and without intellectual disability using GTM1 accelerometers. Participants were 22 adults with mild intellectual disability (ID) and 17 sedentary controls (SC) and nine active controls (AC) without intellectual disability. The proportion of each group achieving 30-minutes of moderate intensity physical activity per day was: ID, 28\%; SC, $47 \%$; and $\mathrm{AC}, 89 \%$. The group with ID did not regularly engage in continuous moderate activity greater than 10 minutes in duration. Primary avenues of activity for ID and SC groups were household chores, yard work, walking and, for the former, Special Olympics; while AC participants engaged in a variety of sports / activities such as jogging and tennis. It was concluded that adults with intellectual disability are similar to the over $50 \%$ of the general population that is classified as sedentary; however the proportion of individuals with intellectual disability accumulating 30-minutes of continuous moderate activity was less than in those without this diagnosis.

Using a larger sample than the accelerometer studies with a broader participant age range, Stanish and Draheim $^{33}$ found fewer adults with intellectual disability met the minimum activity guidelines of the Centers for Disease Control. ${ }^{34}$ Physical activity was assessed using the National Health and Nutrition Examination Survey (NHANES III) and steps per day via pedometry. Participants were 103 adults (65 men and 38 women) 
with mild or moderate intellectual disability. Pedometers were worn for seven consecutive days and survey interviews were conducted with both participants with intellectual disability and direct care providers. Survey data revealed that $17.5 \%$ of participants accrued the recommended duration of 30-minutes per day. Similar findings were reported in studies from England using the criteria of at least 12 bouts of 20 minutes moderate ( $>5$ and $<7.5$ kilocalories per minute) to vigorous ( $\geq 7.5$ kilocalories per minute) activity occurring over four weeks. ${ }^{35-37}$ This threshold had been identified as offering some protection against coronary heart disease ${ }^{38}$ and the proportion of participants meeting this criterion ranged from 4 to 20 per cent.

\section{Walking behavior}

A growing body of evidence suggests that individuals who accumulate 10000 steps per day have less body fat and lower blood pressure than less active individual ${ }^{39,40}$ and fewer steps per day are associated with increased body mass index, waist circumference, and diastolic blood pressure. ${ }^{41}$ Walking is a primary mode of activity in people without disabilities and also appears to be one of the most common physical activities carried out by persons with intellectual disability. ${ }^{30,31,42}$

Despite the prevalence of walking as a primary activity mode, only a handful of studies have actually assessed this health behavior in adults with intellectual disability. Stanish ${ }^{44}$ studied walking behavior in a small sample of 20 individuals with mild intellectual disability (12 females, 8 males aged 19-65 years). Average steps per day for males and females without Down syndrome were $11885 \pm 5646$ and 11 809 \pm 4 652, respectively. When analyzed according to diagnosis, males and females with Down syndrome $(n=9) 5450 \pm 2316$ and $8816 \pm 4094$ acquired fewer steps than those without Down syndrome. Participants walked less on weekends, with nine participants (45\%) achieving 10000 steps or more on weekdays and only four (20\%) achieving this criterion on weekend days. This is contrary to previous research that found no differences in weekend versus weekday physical activity in this population. ${ }^{29}$ In a larger sample of 103 adults, Stanish and Draheim ${ }^{33}$ found that participants with intellectual disability walked an average fewer steps per day (7 832) than the guideline of 10000 steps per day and only $21 \%$ met the same.

Although walking is a prevalent form of physical activity among adults with intellectual disability, the intensity is low or low-moderate and may not be sufficient to promote health..$^{30,31,42}$ Some evidence to support this premise was recently established by Stanish and Draheim, ${ }^{43}$ who found no differences in body composition or blood pressure among adults with intellectual disability who were classified as 'sedentary' (<5 000 steps/day), 'low active' (5 000-7 499 steps/day), 'somewhat active' (7 500-9 999 steps/ day), and 'active' ( $\geq 10000$ steps/day). As Le Masurier ${ }^{45}$ points out, if walking is to be used as an effective physical activity intervention it should be consistent with the current recommendations, particularly with regard to intensity of effort, as well as duration or step counts.

\section{Limitations of approaches used to measure physical activity among adults with intellectual disability}

As previously mentioned, 14 studies have examined lifestyle physical activity among adults with intellectual disability in developed countries. Those studies either sought to describe physical activity levels and patterns among adults with intellectual disability $29-31,35,42,44,46$ or they measured physical activity as a risk factor for non-communicable diseases. ${ }^{18,19,37,47,48}$ Approaches to measuring physical activity varied widely across these studies and there are two major methodological limitations worth noting. The first limitation relates to the validity or accuracy of the actual measurement instrument. None of the questionnaire and interview studies report the accuracy or reliability of the survey instrument used. Two studies ${ }^{47,19}$ used a single item within a questionnaire as an indicator of physical activity without providing evidence of either criterion or predictive validity of the item, and one study ${ }^{18}$ did not provide any details of questions used to elicit physical activity levels. Some preliminary evidence of concurrent validity between care provider diary recordings and accelerometry has been provided by Temple and Walkley ${ }^{31}$ who reported a correlation of .78 over three days of monitoring. In contrast, Frey ${ }^{29}$ found caregivers and adults with intellectual disability had difficulty keeping accurate diaries.

A second limitation was the lack of evidence of accuracy and reliability of those being interviewed or surveyed. A questionnaire or interview was used with adults with intellectual disability and their care provider in four studies. ${ }^{42,46-48}$ However, the authors did not provide evidence of the respondents' ability to provide accurate and reliable information, and did not describe the nature of the care provider's assistance in answering the questions. Since these studies were conducted, Stanish and Draheim ${ }^{33}$ reported that the relationship between total weekly steps (measured via pedometer) and minutes of walking per week or minutes of physical activity per week (derived from the responses to the NHANES III Physical Activity by 
adults with intellectual disability with the assistance of direct care workers) were not significant or meaningful; $r=-.01$ and $r=.06$, respectively. Other studies ${ }^{18,19,35,37}$ used proxy respondents such as parents and care staff without demonstrating the validity of this approach.

The majority of research studies on physical activity and intellectual disability used volunteer participants and the majority of those participants could be characterized as having mild or moderate intellectual disability. ${ }^{27}$ In addition, few studies included comparison groups, and only Frey ${ }^{29}$ provided sufficient details to indicate that the same testing protocol was used. Because the existing studies lack appropriate comparison groups or matched controls it is difficult to determine how active adults with intellectual disability are with relation to the general population.

\section{Levels of physical activity in Latin America}

Obesity and related non-communicable diseases are growing rapidly in Latin America and the Caribbean. Two-six out of 10 adults (53 million) are overweight or obese. ${ }^{1}$ In most parts of Latin America, obesity is already the second most important risk factor for mortality and disease, ${ }^{49}$ and cardiovascular disease is the leading cause of death..$^{50}$ In Mexico, the mortality rate for non-communicable diseases nearly doubled from 1950 to 2000. ${ }^{51}$ Although deaths from coronary heart disease did decline from 1970 to 2000 in Latin America, the reduction was not as favorable as it was in the United States and Canada. ${ }^{52}$ This, and persistent undernutrition, places high demands on economies because of lost productivity and the cost of treating chronic conditions. ${ }^{1}$ For example, Barcelo ${ }^{50}$ estimated that in Mexico the direct costs of diabetes and hypertension will have increased by 11 and $14 \%$ respectively between 2004 and 2006. In developed nations, changes in the environment and lifestyles have resulted in increased consumption of food rich in fat and lower levels of physical activity, both of which contribute to obesity. In developing nations undernutrition and obesity tend to coexist. ${ }^{53}$ However, data from countries in the Region of the Americas indicate half to three quarters of the population are inactive and not meeting WHO minimum physical activity guidelines; ${ }^{49,54}$ and physical inactivity has become one of the five main risk factors for morbidity and mortality in Latin America. ${ }^{55}$

The few studies available related to physical activity in Latin America suggest that a majority of the population is not sufficiently physically active for health. Hallal and coworkers ${ }^{56}$ examined the walking habits of more than 6000 individuals in a southern Brazilian city using the short form of the International Physical
Activity Questionnaire. In 2002, data were collected on all domains (work-related, commuting, leisure) for 3182 individuals, and in 2003 data were collected on leisure time walking only on 3100 individuals. Results from the 'all domains' study indicated that $40 \%$ of participants accrued 150-minutes or more of physical activity per week across three or more days of the week. When compared with the WHO recommendation of 30-minutes of moderate intensity physical activity on five or more days of the week, the percentage of participants achieving the mark dropped to $33.8 \%$-a participation rate lower than the United States average of 45.4 per cent. ${ }^{57}$ When Hallal and coworkers considered only leisure time physical activity, $10 \%$ of those surveyed achieved 30-minutes of moderate intensity physical activity on five or more days of the week. Higher socioeconomic status, level of education, and increased age (until 70+ years) were positively associated with levels of physical activity.

The level of leisure time physical activity reported by Hallal and coworkers was higher than Monteiro and colleagues' earlier study of leisure time physical activity in Brazil..$^{58}$ These authors found that among 11033 Brazilians, only $3 \%$ engaged in the WHO recommended levels of physical activity during leisure time. The main form of physical activity reported by participants who accrued 30-minutes of moderate intensity physical activity on five or more days per week was walking/ jogging $(m e n=66 \%$, women $=81 \%)$. Team sport was a relatively common source of physical activity among men, particularly for those who engaged in less regular activity. Among women, sports were not a common source of physical activity. After walking, going to the gym/muscular exercise was the second most frequent form of physical activity for women.

Two other published manuscripts from Latin America suggest that levels of physical activity are low. Data published from the National Household Survey of Peru indicate that $12.8 \%$ of men and $10.5 \%$ of women engage in regular sports activity. ${ }^{59}$ Regular sports activity was defined as engaging in sport either every day or every other day. Although these findings are difficult to compare with the WHO recommendation for physical activity, they do suggest that levels of physical activity are low. Seclen-Palacin and Jacoby ${ }^{59}$ also reported that levels of regular sports activity were positively associated with higher levels of formal education and employment status (employed vs. unemployed). Levels of physical activity were lowest in metropolitan Lima (10.6\%) compared with other regions of Peru, and were highest among men aged 50-55 years and women aged 40-45 years. Salinas et al. ${ }^{60}$ also cited urbanization as an important factor associated with low levels of physical activity in Chile. These authors reported that $9 \%$ of the 
Chilean population engaged in 30-minutes of physical activity on three or more days of the week.

Leisure time physical activity and physical activity in general was higher for women in Mexico than the previously cited studies on physical activity in Latin America. Hernandez and coworkers ${ }^{61}$ found that among a National sample $(n=2367)$ of girls and women (aged 12-49 years) in Mexico, average participation in physical activity was relatively high. Constructs of physical activity examined were engagement in vigorous physical activity ( $\geq 5$ metabolic equivalents) and engagement in sedentary activities (watching television, sitting while working and the like). Two questions were used to examine sport and habitual exercise as a specific sub-set of vigorous physical activity. Participants were asked whether they had engaged in any sport or physical exercise on the day before the interview or habitually e.g. run, walk, bicycle, dance, swim, or play volleyball. If the response was positive, participants were asked how much time they spent in sports and exercise (either the day before the interview or in the last week). Results indicated that an average of 1.25 hours per day was spent in vigorous physical activity. Of the time spent in vigorous physical activity, 0.08 hours ( \pm 0.27 hours) was spent in sport or habitual exercise. Nine percent of the women indicated that they spent an hour engaged in sport or exercise on the previous day, and 15.9\% of participants said they engaged in sport or exercise regularly. Girls and women younger than 21 years of age and those with less than a secondary education were more likely to be inactive. Hernandez and coworkers did not set out to measure energy expenditure or moderate intensity physical activity consistent with the WHO recommendations; rather their intent was to identify the most and least active women in the sample. However, their findings related to vigorous physical activity suggest that many women in Mexico currently meet WHO recommendations for physical activity and perhaps Mexican women are more active than women elsewhere in Latin America. In addition, consistent with findings of Monteiro and coworkers ${ }^{58}$ lifestyle physical activity, rather than sports and exercise, was the major source of physical activity.

The limited published data on participation in physical activity in Latin America suggest that less than one third of those surveyed are meeting the WHO recommendation for physical activity across all domains. When leisure time physical activity is considered, the proportion drops to $10 \%$ or less. Women in Mexico may be more active than others in Latin America, and major forms of physical activity are walking and lifestyle activities. Those most likely to be active are older and have higher formal education. The trend for those in the 30-50 year age group to be more active than those in their twenties or late teens is not typical of developed nations, ${ }^{62}$ suggesting that patterns of participation in physical activity in Latin America may be somewhat unique.

\section{Levels of physical activity among adults with intellectual disability in Latin America}

Fujiura and coworkers ${ }^{28}$ rhetorically asked "How much of the world's population lives with a disability and what are the circumstances of their lives?" Their answer was that the current state of knowledge can be summarized as "we really do not know" (p. 296). This is apparent for participation in physical activity among adults with intellectual disability in Latin America and the developing world in general.

It is known that there are more than 200000 Special Olympics athletes in Latin America and there are Special Olympics offices in Panama, Santiago, Lima, and Caracas. ${ }^{63}$ Latin American athletes participate in a diverse array of sports including football, alpine and cross-country skiing, team handball, tennis, and bocce. Moreover, it is known there has been phenomenal growth in participation in Special Olympics in Mexico. In 2000, an estimated 5000 athletes participated in Special Olympics in Mexico, whereas by 2006, 22000 athletes participated.* This growth may be indicative of the increased awareness of the benefits of physical activity for persons with intellectual disability; as well as some untapped demand for programs.

In the absence of physical activity data; physical fitness levels of persons with intellectual disability have been examined as indicators of participation in physical activity. Research in developed countries consistently shows that individuals with intellectual disability are less fit than their peers without a disability, and that fitness levels are generally low. ${ }^{21,64,65}$ Although no data from Latin America were available, three studies of fitness among adolescents with intellectual disability in Thailand and Africa suggest that this pattern also applies in developing countries. Percent body fat, cardiorespiratory endurance, flexibility, and muscular endurance were evaluated for 28 adolescents with mild to moderate intellectual disability and 14 peers without a disability in Bangkok. Results indicated that adolescents with intellectual disability had low cardiorespiratory endurance, leg strength, and flexibility. ${ }^{66}$ More

\footnotetext{
* Beth Alldridge, Special Olympics North America, personal communication, 15 January 2007.
} 
definitively, Onyewadume ${ }^{67}$ compared fitness levels of Black African early adolescents with and without mild intellectual disability in Botswana. Adolescents without intellectual disability had significantly better percent body fat, grip strength, trunk flexion, combined back and leg strength, vertical jump, push ups, and Rockport walking test scores than adolescents with mild intellectual disability. In an earlier study, Onyewadume and Amusa $^{68}$ demonstrated that adolescent African Special Olympic athletes preparing for the 10th Special Olympics World Summer Games had low levels of fitness on all components of fitness measured (BMI, percent body fat, selected muscle circumferences, trunk flexion and extension, grip and back strength, jumping, sit ups, push ups, and cardio-respiratory endurance).

The available information related to the participation in physical activity by persons with intellectual disability suggests that very little is known, but that there is interest in being physically active. Data from developing nations outside of Latin America indicate that persons with intellectual disability have poorer fitness profiles than those without intellectual disability; a pattern consistent with developed countries. On the whole, physical activity for persons with intellectual disability receives little attention in both developed and developing nations.

\section{Conclusions}

The health benefits of physical activity have been recognized for more than three decades, and there is burgeoning interest in physical activity for health in Latin America. Evidence from studies conducted in the developed world suggests that less than one third of adults with intellectual disability are sufficiently active for health. On the whole, these studies were conducted on persons with mild intellectual disability with few mobility difficulties. Therefore these rates of physical activity are likely to be inflated. Methodological limitations of studies conducted to date do not permit rigorous analysis of differences in activity patterns between adults with and without intellectual disability.

Mortality due to non-communicable diseases such as cardiovascular disease is high in Latin American countries and it appears that a majority of the general population is inactive. However, virtually nothing is known about the physical activity levels of adults with intellectual disability. This implies that even if levels of participation mirror the general population, persons with intellectual disability would largely be inactive and at risk for non-communicable diseases; but this is speculation. This much is known: that participation in Special Olympics in Latin America is growing; which suggests that there may be increasing awareness of the need for physical activity among persons with intellectual disability and a demand for programs.

The Pan American Health Organization ${ }^{1}$ suggests that timely and accurate information on the patterns of physical activity is needed for policy-making, planning, program implementation, and measuring progress and success. Although the Pan American Health Organization may not have been referring to sub-populations such as persons with intellectual disability; collection of data on this population is important. Data such as these are important because very little has been gathered about participation in physical activity by persons with intellectual disability outside of developed countries. Having baseline data on activity levels and barriers to participation for persons with intellectual disability and persons without disability set the stage for both advocacy and reform. When data exist is it easier to convince government and non-governmental organizations of the need to develop and implement supportive policies, programs, and environments.

Based on the findings from the studies conducted on physical activity and intellectual disability in developed countries the following comments are provided for consideration by those interested in the measurement and facilitating of physical activity among adults with intellectual disability in Latin America. Specific approaches to intervention are not mentioned here as they are reported in another paper in this special issue.

1. Motion sensors (pedometers and accelerometers) have been used successfully with adults with intellectual disability. They provide a direct and objective measure of physical activity; and do not rely on participant or proxy recall. In addition, pedometers are relatively inexpensive. Accordingly, using motion sensors to assess physical activity among adults with intellectual disability is worth considering; and at the present time, the most valid approach to measuring physical activity in this population.

2. In the general population, when direct observation or the use of motion sensors is neither practical nor ideal, questionnaires are often used. They provide inexpensive and relatively unobtrusive estimates of physical activity. However, people with intellectual disability exhibit delays in cognitive functioning, including attention, memory, generalization, and language/ communication. To date, very little work has been done to validate the use of questionnaires with persons with intellectual disability, with proxy respondents (such as parents or care providers), or with both an individual with intellectual disability 
and a key support person. Therefore, before questionnaires are used for research or public health purposes in this population, validation work needs to be done to determine whether the data will be useful.

3. The most common form of physical activity among persons with intellectual disability is walking. Dr. Enrique Jacoby noted that walking is seen as a best solution to the problem of insufficient physical activity in the Americas. ${ }^{53}$ This is also likely to be a very good solution for people with intellectual disability. Notwithstanding the growing presence of Special Olympics in the region and the joy and challenges of playing sport, lifestyle intervention is recommended. Building physical activity into everyday through purposeful activity such as gardening, engaging in chores around the house, walking for transport, and walking for exercise. Physical activity that is built into everyday life is more likely to be sustainable.

The life expectancy of people with intellectual disability is increasing. Accordingly, more attention has been given to preventing secondary disabling conditions and non-communicable diseases like obesity, diabetes, and hypertension in efforts to improve overall health and quality of life. Promoting moderate levels of physical activity among people with intellectual disability is an important goal for public health and public policy. An important component of this process is to establish current physical activity levels of persons with intellectual disability in Latin America. Valid, reliable data is a sine qua non condition for the evaluation of the health situation, decision-making, and programming for health, ${ }^{1}$ and for advocacy.

\section{References}

I. Pan American Health Organization. Health indicators: Building blocks for health situation analysis. In: Epidemiol Bull 200 I;22:I-5.

2. Bauman A, Bellew B, Vita P, Brown W, Owen N. Getting Australia active: Towards better practice for the promotion of physical activity. Melbourne, Australia: National Public Health Partnership;2002:iii.

3. US Department of Health and Human Services. Healthy People 2010: Understanding and improving health. 2nd ed. Washington, DC: US Government Printing Office, 2000.

4. World Health Organization.WHO global strategy on diet, physical activity and health; 2005. Available from http://www.who.int/ dietphysicalactivity/media/en/gsfs_pa.pdf. [Accessed on 6 December 2006]. 5. Pate RR, Pratt M, Blair SN, et al. Physical activity and public health:A recommendation from the Centers for Disease Control and Prevention and the American College of Sports Medicine.J Am Med Assoc 1995;273:402-407.
6. Haapanen N, Miilunpalo S,Vuori I, Oja P, Pasanen M. Characteristics of leisure time physical activity associated with decreased risk of premature all-cause and cardiovascular disease mortality in middle-aged men. Am J Epidemiol 1996; I43:870-880.

7. Gaylord V, Lieberman L,Abery B, Lais G. Social inclusion through recreation:What's the connection? Impact: Feature Issue on Social Inclusion Through Recreation for Persons with Disabilities 2003;16:2-3,32. 8.Vainio H, Bianchini F, eds. Weight control and physical activity (Vol. 6). Lyon: IARC Press, 2002.

9. Frisancho AR. Reduced rate of fat oxidation:A metabolic pathway to obesity in developing nations. Am J Hum Biol 2003; 15:522-532. I0. Ford ES, Giles WH, Dietz WH. Prevalence of the Metabolic Syndrome among US Adults. Findings from the third National health and nutrition survey. JAMA 2002;287:356-359.

II. Katzmarzyk PT, Leon AS, Wilmore JH, Skinner JS, Rao DC, Rankinen T, et al. Targeting the metabolic syndrome with exercise: Evidence from the HERITAGE Family Study. Med Sci Sports Exerc 2003;35: 1703-1709.

12. Layne JE, Nelson ME. The effects of progressive resistance training on bone density:A review. Med Sci Sports Exerc 1999;31:25-30.

13. Roth SM, Ferrel RE, Hurley BF. Strength training for the prevention and treatment of sarcopenia.J Nutr Health Aging 2000; 4: I 43-I55.

14.American Geriatrics Society, British Geriatrics Society, and American Academy of Orthopaedic Surgeons Panel on Falls Prevention. Guidelines for the prevention of falls in older persons. J Am Geriatr Soc 2001;49: 664-672.

15. Sutherland G, Couch MA, lacono T. Health issues for adults with developmental disability. Res Dev Disabil 2002;23:422-445.

16. Draheim C. Cardiovascular disease prevalence and risk factors of persons with mental retardation. Ment Retard Dev Disabil Res Rev 2006;12:3-12.

17. Draheim CC, McCubbin JA, Williams DP. Differences in cardiovascular disease risk between non-diabetic adults with Down syndrome and mental retardation. Am J Ment Retard 2002;107:20I-2II.

18. Janicki MP, Davidson PW, Henderson CM, McCallion P, Taets JD, Force $\mathrm{LT}$, et al. Health characteristics and health services utilization in older adults with intellectual disability living in community residences.J Intellect Disabil Res 2002;46:287-298.

19. Rimmer JH, Braddock D, Marks B. Health characteristics and behaviors of adults with mental retardation residing in three living arrangements. Res Dev Disabil 1995; 16:489-499.

20. Rimmer JH,Yamaki K. Obesity and intellectual disability. Ment Retard Dev Disabil Res Rev 2006; 12:22-27.

21. Fernhall B, Pitetti KH. Limitations to physical work capacity in individuals with mental retardation. Clin Exerc Physiol 2001;3: 176-185. 22. Graham A, Reid G. Physical fitness of adults with an intellectual disability:A I3-year follow-up study. Res Q Exerc Sport 2000;71:152-161. 23. Center JR, Beange H, McElduff A. People with mental retardation have an increased prevalence of osteoporosis:A population study.Am J Ment Retard 1998; 103:19-28.

24. Center JR, McElduff A, Beange H. Osteoporosis in groups with intellectual disability. Australian and New Zealand Journal of Developmental Disabilities 1994; 19:251-258.

25. Felix M, McCubbin J, Shaw J. Bone mineral density, body composition, and muscle strength in premenopausal women with mental retardation. Adapt Phys Activ Q 1998; 15:345-356.

26. Foster BL, Walkley JW, Temple VA. An examination of the bone mineral density of women with an intellectual disability.Adapt Phys Activ $Q$ 2001;18:49-59.

27. Temple VA, Frey GC, Stanish HI. Physical activity of adults with mental retardation. Review and research needs. Am J Health Promot 2006;21:2-12. 28. Fujiura GT, Park HJ, Rutkowski-Kmitta V. Disability statistics in the developing world:A reflection on the meanings in our numbers. Journal of Applied Research in Intellectual Disabilities 2005;18:295-304. 
29. Frey G. Comparison of physical activity levels between adults with and without mental retardation.J Phys Act Health 2004; I:235-245. 30. Temple VA, Anderson C, Walkley JW. Physical activity levels of individuals living in a group home.J Intellect Dev Disabil 2000;25:327-34I. 31. Temple VA, Walkley JW. Physical activity of adults with intellectual disability.J Intellect Dev Disabil 2003;28:323-334.

32. Bouchard C, Tremblay A, Leblanc C, Lortie G, Savard R. Method to assess energy expenditure in children and adults. Am J Clin Nutr | 983;37:46|-467.

33. Stanish $\mathrm{HI}$, Draheim CC.Assessment of walking activity using a pedometer and survey in adults with mental retardation. Adapt Phys Activ Q 2005;22:136-145.

34. U.S. Department of Health and Human Services. Physical activity and health:A report of the Surgeon General.Atlanta, Georgia: US Department of Health and Human Services, Public Health Service, CDC, National Center for Chronic Disease Prevention and Health Promotion, 1996. 35. Emerson E. Underweight, obesity and exercise among adults with intellectual disabilities in supported accommodation in Northern England. J Intellect Disabil Res 2005;49:134-I43.

36. Messent PR, Cooke CB, Long J. Physical activity, exercise and health of adults with mild and moderate learning disabilities. British Journal of Learning Disabilities 1998;26:17-22.

37. Robertson J, Emerson E, Gregory N, Hatton C, Turner S, Kessissoglou $\mathrm{S}$, et al. Lifestyle related risk factors for poor health in residential settings for people with intellectual disabilities. Res Dev Disabil 2000; 2I, 469-486. 38. Department of Health. The Health Survey for England 1993. London: HMSO, 1995.

39. Moreau KL, Degarmo R, Langley J, McMahon C, Howley ET, Bassett DR, et al. Increasing daily walking lowers blood pressure in postmenopausal women. Med Sci Sports Exerc 200I; 33:1825-1831. 40.Tudor-Locke C,Ainsworth BE, Whitt MC, Thompson RW,Addy CL, Jones DA. The relationship between pedometer-determined ambulatory activity and body composition variables. Int J Obes Relat Metab Disord 200I; 25:I57I-I578.

4I. Chan CB, Spangler E,Valcour J,Tudor-Locke C. Cross-sectional relationship of pedometer-determined ambulatory activity to indicators of health. Obes Res 2003; II:I563-1570.

42. Draheim CC,Williams DP, McCubbin JA. Prevalence of physical inactivity and recommended physical activity in community-based adults with mental retardation. Ment Retard 2002; 40:436-444.

43. Stanish HI, Draheim CC. Walking activity, body composition, and blood pressure in adults with intellectual disabilities. Journal of Applied Research in Intellectual Disabilities 20:183-190.

44. Stanish HI.Accuracy of pedometers and walking activity in adults with mental retardation. Adapt Phys Activ Q 2004; 21:167-179.

45. Le Masurier GG. Walk which way? ACSM's Health \& Fitness Journal 2004; 8:7-10.

46. Messent PR, Cooke CB, Long J. Daily physical activity in adults with mild and moderate learning disabilities: Is there enough? Disabil Rehabil 1998; 20:424-427.

47. Beange H, McElduff A, BakerW. Medical disorders of adults with mental retardation:A population study.Am J Ment Retard 1995; 99:595-604. 48. Wells MB, Turner S, Martin DM, Roy A. Health gain through screeningcoronary heart disease and stroke: Developing primary health care services for people with intellectual disability.J Intellect Dev Disabil 1997; 22:25I-263.
49. World Health Organization. The world health report 2002. Reducing risks, promoting healthy life. Geneva 2002.

50. Barcelo A. Cardiovascular diseases in Latin America and the Caribbean. Lancet 2006; 368:625-626.

51. Consejo Nacional de Poblacion. La situacion demografica de Mexico 2000. Mexico, DF. Consejo Nacional de Población, 200I.

52. Rodriguez T, Malvezzi M, Chatenoud L, Bosetti C, Levi F, Negri E, et al. Trends in mortality from coronary heart and cerebrovascular diseases in the Americas: 1970-2000. Heart 2006; 92:453-460.

53. Centers for Disease Control and Prevention and the World Health Organization. CDC/WHO Partners Meeting: Implementation of WHO Physical Activity Strategy. Geneva:WHO, 2004.

54. Pan American Health Organization. Physical Activity Fact Sheet \#3, Physical Inactivity:A major health risk factor in the Americas. In P.A.S. B. R. O. o. t.W. H. O. Food and Nutrition Program/Division of Health Promotion and Protection, 2002: Author.

55. Jacoby E, Bull F, Neiman A. Rapid changes in lifestyle make increased physical activity a priority for the Americas. Pan Am J Public Health 2003;14:226-228.

56. Hallal PC,Azevedo MR, Reichert FF, Siqueira FV,Araujo CLP,Victora CG. Who, when, and how much? Epidemiology of walking in a middleincome country. Am J Prev Med 2005; 28:156-161.

57. Centers for Disease Control and Prevention. Prevalence of physical activity, including lifestyle activities among adults - United States, 2000200I. Morbidity and Mortality Weekly Report 2003; 52:764-769.

58. Monteiro CA, Conde WL, Matsudo SM, Matsudo VR, Bonsenor IM, Lotufo PA.A descriptive epidemiology of leisure-time physical activity in Brazil, 1996-1997. Pan Am J Public Health 2003; 14:246-253.

59. Seclen-Palacin JA, Jacoby ER. Sociodemographic and environmental factors associated with sports physical activity in the urban population of Peru. Pan Am J Public Health 2003; 14:255-264.

60. Salinas J,Vio F. Promoting health and physical activity in Chile:A policy priority. Pan Am J Public Health 2003; 14:28I-288.

61. Hernandez B, de Haene J, Barquera S, Monterrubio E, Rivera J, Shamah

$\mathrm{T}$, et al. Factors associated with physical activity among Mexican women of childbearing age. Rev Panam Salud Publica 2003; 14:235-245.

62. US Department of Health and Human Services. Physical activity fundamental to preventing disease. In O. o. t.A. S. f. P. a. Evaluation, 2002: Author.

63. Special Olympics. Latin America, 2007, from http://www. specialolympics.org. [Acceced 12 January 2007]

64. Pitetti KH,Yarmer DA. Lower body strength of children and adolescents with and without mental retardation:A comparison. Adapt Phys Activ Q 2002; 19:68-81.

65. Pitetti KH,Yarmer DA, Fernhall B. Cardiovascular fitness and body composition of youth with and without mental retardation. Adapt Phys Activ Q 200I; |8:|27-|4|.

66. Chaiwanichsiri D, Sanguanrungsirikul S, Suwannakul W. Poor physical fitness of adolescents with mental retardation at Rajanukul School, Bangkok.J Med Assoc Thai 2000; 83:I387-1392.

67. Onyewadume IU. Fitness of black African early adolescents with and without mild mental retardation. Adapt Phys Activ Q 2006; 23:277-292. 68. Onyewadume IU,Amusa LO. Physical fitness profile of Special Olympic-bound athletes: Implications for performance success, injury proneness and future preparations. Research Bi-annual for Movement 2002; 18:18-36. 